\title{
Desempenho produtivo e saúde de cordeiros lactentes consumindo sucedâneos lácteos com diferentes proporções de lactose
}

\author{
Growth performance and health of lactating lambs consuming milk replacers with different \\ proportions of lactose
}

\author{
Marcelo Vedovatto $^{1 *}$, Luis Henrique Ebling Farinatti ${ }^{2}$ e Cristiano Todero $^{3}$ \\ ${ }^{1}$ Universidade Federal de Mato Grosso do Sul, Campo Grande, MS, Brasil. *Autor para correspondência: mv.vedovatto@gmail.com. \\ ${ }^{2}$ Universidade Federal do Acre, Cruzeiro do Sul, AC, Brasil. \\ ${ }^{3}$ Universidade do Estado de Santa Catarina, Lages, SC, Brasil.
}

Submissão: 08/07/2018 / Aceite: 05/04/2019

\begin{abstract}
RESUMO
Objetivou-se avaliar o ganho de peso, consumo de alimentos e a saúde de cordeiros lactentes da raça Lacaune consumindo leite de ovelha ou sucedâneos lácteos com diferentes proporções de lactose (LAC). Foram utilizados 36 cordeiros machos lactentes, com aproximadamente seis dias de idade $(4,98 \pm 1,20$ $\mathrm{kg}$ ) e avaliados até o desmame (60 dias de idade). Estes foram divididos em 12 lotes, com três animais cada, e alojados em baias, correspondendo a quatro baias por tratamento. Os tratamentos experimentais foram: Leite de ovelha; Sucedâneo 36\% LAC, sucedâneo lácteo contendo 36\% de lactose e; sucedâneo $29 \%$ LAC, sucedâneo lácteo contendo $29 \%$ de lactose. Os cordeiros alimentados com sucedâneo $29 \%$ LAC apresentaram menores $(p \leq 0,05)$ peso corporal final, ganho médio diário, consumo total de alimentos e pior conversão alimentar, em relação aos animais do tratamento Leite de ovelha. Os cordeiros que receberam Sucedâneo 36\% LAC não diferiram ( $p>0,05)$ dos animais dos tratamentos Leite de ovelha e Sucedâneo $29 \%$ LAC para as variáveis acima citadas. Não houve efeito de tratamento $(p>0,05)$ na taxa de mortalidade ou na ocorrência de diarreia. Assim, o Sucedâneo 36\% LAC pode substituir o Leite de ovelhas sem prejuízos ao desempenho, consumo e saúde dos cordeiros, porém a utilização do sucedâneo 29\% LAC, apesar de não ter afetado a saúde, pode reduzir o desempenho e o consumo de alimentos pelos cordeiros.
\end{abstract}

PALAVRAS-CHAVE: aleitamento artificial, amamentação, Lacaune, ovinos.

\begin{abstract}
The objective was to evaluate growth performance, feed intake and health by suckling Lacaune lambs consuming ewe's milk or milk replacers with different lactose (LAC) ratios. Thirty-six male lambs with approximately six days of age $(4,98 \pm 1,20 \mathrm{~kg})$ were used, and evaluated until weaning (60 days of age). These were divided in 12 cohorts, with three animals each, and housed in pens, corresponding to four pens per treatment. The experimental treatments were: Ewe's milk; Milk replacer $36 \%$ LAC, milk replacer containing $36 \%$ of lactose and; Milk replacer $29 \%$ LAC, milk replacer containing $29 \%$ of lactose. The lambs fed with Milk replacer $29 \%$ LAC showed lower $(p \leq 0.05)$ final body weight, average daily gain, total feed intake and worse feed conversion, in relation to the animals treated with Ewe's milk. The lambs that received Milk replacer 36\% LAC did not differ ( $p>0.05$ ) from the animals treated with Ewe's milk and Milk replacer $29 \%$ LAC for the variables mentioned above. There was no treatment effect $(p>0.05)$ on the mortality or diarrhea rate. Thus, Milk replacer 36\% LAC can replace the Ewe's milk without impairing growth performance, intake and health of lambs, but the use of the Milk replacer $29 \%$ LAC, despite not having affected the health, can reduce the growth performance and feed intake in lambs.
\end{abstract}

KEYWORDS: artificial milk, suckling, Lacaune, sheep.

\section{INTRODUÇÃO}

Em sistemas de produção intensiva de ovinos de leite, os cordeiros normalmente permanecem os primeiros dias de vida junto as mães para consumir colostro e na sequência são separados e passam a receber sucedâneos lácteos (HERNÁNDEZ-CASTELLANO et al. 2015) até aproximadamente 45-60 dias, quando são desmamados. Essa estratégia além de facilitar o manejo (EMSEN et al. 2004), permite destinar 
maior quantidade de leite ao processamento (NAPOLITANO \& ROSA 2008), principalmente para a produção de queijos. Como o valor de compra dos sucedâneos lácteos pelos produtores normalmente é inferior ao valor recebido na comercialização do leite de ovelha com o laticínio, o aleitamento artificial se tornou prática comum na ovinocultura leiteira.

$\mathrm{Na}$ ovinocultura leiteira, o nascimento de fêmeas é interessante, pois essas serão utilizadas principalmente para repor o descarte de matrizes, aumentar o rebanho ou então são destinadas a venda. Porém, os cordeiros machos nem sempre são economicamente viáveis, pois, caso não sejam vendidos como reprodutores, precisam ser recriados para serem abatidos. Raças de aptidão leiteira como Lacaune, produzem cordeiros com menor ganho de peso que raças específicas para produção de carne, e assim o custo do aleitamento precisa ser reduzido para que seja economicamente viável sua produção. Desta forma, o aleitamento artificial pode ser empregado para essa categoria.

Diversos trabalhos testaram a utilização de sucedâneos lácteos, das mais diversas composições para cordeiros e, alguns observaram ganho de peso similar aos que consumiram leite de ovelha (EMSEN et al. 2004, HERNÁNDEZ-CASTELLANO et al. 2015) e outros ganho de peso inferior (LANZA et al. 2006, OCAK \& CANKAYA 2013). Além das diferenças nos sistemas de produção nas pesquisas supracitadas, raça, sexo, tipo de parto e, principalmente, a composição dos sucedâneos lácteos, influenciaram os resultados. Segundo UMBERGER (1997) o sucedâneo lácteo de alta qualidade para cordeiros deve possuir em sua composição: $22-24 \%$ de proteína bruta, $25-35 \%$ de extrato etéreo, menos de $1 \%$ de fibra bruta e $5-8 \%$ de cinzas. Porém, EMSEN et al. (2004) verificaram que sucedâneos com menor concentração de extrato etéreo (19\%), normalmente utilizados em sucedâneos fornecidos para bezerros, podem ser utilizados para cordeiros sem prejuízo ao desempenho.

Assim o objetivo deste trabalho foi avaliar o desempenho produtivo e a saúde de cordeiros lactentes da raça Lacaune consumindo leite de ovelha ou sucedâneos lácteos com diferentes proporções de lactose.

\section{MATERIAL E MÉTODOS}

O experimento foi conduzido em fazenda comercial, localizada no município de Planalto Alegre, Santa Catarina, Brasil. Foram utilizados, 36 cordeiros machos lactentes da raça Lacaune, com aproximadamente seis dias de idade e peso vivo de 4,98 $\pm 1,20 \mathrm{~kg}$. Os animais foram identificados com brincos auriculares, e divididos pela data de nascimento, peso corporal, e tipo de parto (simples, duplo ou triplo) em 12 lotes com três animais cada. Cada lote foi alojado em baia coletiva de seis metros quadrados de área que continha em seu interior um bebedouro, um comedouro para fornecimento concentrado, e uma estrutura suspensa confeccionada de tela de arame para fornecimento de feno. Embaixo dessa estrutura, permanecia uma base de madeira com o objetivo de evitar desperdício do feno. O piso das baias era de concreto e foi coberto com maravalha, a qual era trocada periodicamente.

Os cordeiros foram distribuídos nos seguintes tratamentos experimentais: Leite de ovelha; Sucedâneo 36\% LAC, sucedâneo lácteo contendo 36\% de lactose (Sprayfo Red, Trouw Nutrition, Holanda) e; Sucedâneo 29\% LAC, sucedâneo lácteo contendo $29 \%$ de lactose (produto sem nome comercial - em fase de teste, (Raupp Comércio e Importação Ltda. Brasil) (Tabela 1). Os sucedâneos eram diluídos em água aquecida a $37^{\circ} \mathrm{C}$, na proporção de 1:6 respectivamente, e o leite de ovelha também era aquecido a essa mesma temperatura. O leite e os sucedâneos eram fornecidos manualmente com a utilização de mamadeiras graduadas, com $250 \mathrm{~mL}$ de leite de ovelha ou sucedâneo lácteo por cordeiro a cada refeição (duas refeições diárias, as 8:00 h e 16:00 h), sendo anotadas as sobras quando presentes. Após cada aleitamento, as mamadeiras eram lavadas e desinfetadas.

Tabela 1. Composição química do leite de ovelha e dos sucedâneos lácteos.

Table 1. Chemical composition of ewe's milk and milk replacers.

\begin{tabular}{lccccc}
\hline & \multicolumn{5}{c}{ Alimentos } \\
\cline { 2 - 6 } & & \multicolumn{4}{c}{ Sucedâneo } \\
\cline { 2 - 6 } \multicolumn{1}{c}{ Composição química } & $\begin{array}{c}\text { Leite de } \\
\text { ovelha }\end{array}$ & $36 \%$ LAC $^{1}$ & $29 \%$ LAC $^{1}$ & $\begin{array}{c}36 \% \text { LAC } \\
\text { (diluído) }^{2}\end{array}$ & $29 \%$ LAC \\
(diluído) $^{2}$
\end{tabular}

${ }^{1}$ Níveis de garantia dos sucedâneos. Sucedâneo 36\% LAC, sucedâneo lácteo contendo 36\% de lactose (Sprayfo Red, Trouw Nutrition, Holanda) e; Sucedâneo $29 \%$ LAC, sucedâneo lácteo contendo $29 \%$ de lactose (produto sem nome comercial - em fase de teste, Raupp Comércio e Importação Ltda, Brasil).

² Sucedâneos lácteos diluídos em água na proporção de 1:6 respectivamente. 
Inicialmente, os animais passaram por cinco dias de adaptação aos tratamentos, e nesse período, os cordeiros permaneceram durante o dia alojados em suas respectivas baias e durante a noite, junto com as mães. Para os animais dos grupos que receberam sucedâneos, somente nessa fase, os sucedâneos eram diluídos com leite de ovelha na proporção de 1:1. Após esse período (aproximadamente 11 dias de idade) os cordeiros permaneceram em tempo integral nas baias e os sucedâneos eram diluídos somente em água.

$\mathrm{O}$ alimento concentrado foi fornecido somente no período da manhã $(8: 00 \mathrm{~h})$ e o consumo foi $a d$ libitum. Anterior a isso, eram recolhidas as sobras referentes ao dia anterior, pesadas e anotadas. Foram formulados três tipos de concentrados, para serem fornecidos de acordo com o desenvolvimento dos animais (6-25 dias, 26-48 dias, 49-60 dias) (Tabela 2). O feno utilizado foi de tifton 85 (Cynodon spp.), também fornecido ad libitum. Semanalmente, todo o feno acondicionado nas telas suspensas, era recolhido e pesado. O consumo dos alimentos foi calculado, subtraindo-se o total fornecido pelas sobras.

Tabela 2. Descrição dos ingredientes e composição química dos concentrados e do feno de tifton 85 (Cynodon spp.).

Table 2. Description of the ingredients and chemical composition of concentrates and tifton 85 hay (Cynodon spp.).

\begin{tabular}{lrrrr}
\hline Itens & \multicolumn{4}{c}{ Alimentos } \\
\hline & & \multicolumn{3}{c}{ Concentrados } \\
\cline { 3 - 5 } Ingredientes (\%) & Feno & $6-25$ dias & $26-48$ dias & $49-60$ dias \\
\hline Farelo de soja & - & 65 & 50 & 35 \\
Milho & - & 27 & 42 & 57 \\
Leite em pó & - & 5 & 5 & 5 \\
Mistura mineral & - & 3 & 3 & 3 \\
\hline Composição química (\%) & & & 89,10 & 88,95 \\
\hline Matéria seca & 87,46 & 89,25 & 27,64 & 21,94 \\
Proteína bruta & 6,93 & 33,34 & 13,96 & 13,86 \\
Fibra em detergente neutro & 78,01 & 14,07 & 45,51 & 52,19 \\
Carboidrato não fibroso & 11,94 & 38,84 & 5,88 & 5,72 \\
Extrato etéreo & 1,54 & 6,05 & 7,00 & 6,29 \\
Matéria mineral & 6,43 & 7,70 &
\end{tabular}

Amostras dos concentrados, feno, sucedâneos e leite de ovelha foram enviadas à laboratório comercial (MercoLab Laboratórios Ltda., Chapecó, SC, Brasil) para realização das análises químicas. Resumidamente os concentrados e o feno foram analisados segundo o AOAC (1990): matéria seca (MS), método 930.15; proteína bruta (PB), método 976.05; extrato etéreo ( $E E)$, método 920.39 e matéria mineral (MM), método 942.05. A concentração de fibra em detergente neutro (FDN) foi analisada segundo a metodologia de VAN SOEST et al. (1991) e a de carboidratos não fibrosos (CNF) segundo a equação de SNIFFEN et al. (1992): 100 - (Cinzas + PB + FDN + EE). Para o leite de ovelha foram feitas análises de MS, PB, EE e lactose em um equipamento de NIRS (Near Infra Red Spectro) devidamente calibrado.

Os animais foram pesados ao início do experimento (aproximadamente seis dias de idade) e novamente com 11, 18, 25, 32, 39, 48 e 60 dias de idade. O ganho médio diário (GMD) dos animais foi calculado pela diferença entre os pesos final e inicial, dividida pelo número de dias em cada intervalo de avaliação. A conversão alimentar (CA) foi calculada através da divisão do total de alimentos consumidos pelo ganho de peso. Além disso, diariamente os cordeiros eram avaliados quanto à presença de diarreia e, quando necessário, medicados.

O delineamento experimental foi de blocos inteiramente casualizados, com quatro repetições (baias) por tratamento. Os dados de peso corporal (PC), GMD, consumo e CA foram analisados pelo procedimento MIXED do SAS (2013) com a aproximação Satterthwaite para determinar os graus de liberdade do denominador para efeitos fixos. Os modelos estatísticos continham como efeito fixo tratamento e para as variáveis $\mathrm{PC}, \mathrm{GMD}$, e consumo de leite ou sucedâneos foi utilizado como variável aleatória, animal (tratamento) e animal (baia) e, para as variáveis consumo de feno, concentrado, total e CA como variável aleatória baia (tratamento). Os dados binários de taxa de mortalidade e diarreia foram analisados pelo procedimento GLIMMIX do SAS (SAS 2013), com a aproximação Satterthwaite para determinar os graus de liberdade do denominador para efeitos fixos. Os modelos estatísticos continham como efeito fixo tratamento e, como variável aleatória, animal (tratamento) e animal (baia). Para todas as análises a função pdiff foi utilizada quando detectada significância no teste-F e todos os resultados são reportados como LSMEANS seguidos por erro padrão da média (EPM). A significância foi definida quando $p \leq 0,05$. 


\section{RESULTADOS}

O consumo de leite ou sucedâneos diferiu $(p \leq 0,05)$ entre os tratamentos no início do experimento (611 dias). Nesse período, o maior consumo foi de Leite de ovelha, seguido por Sucedâneo $36 \%$ LAC e Sucedâneo 29\% LAC. Após esse período não houve diferença $(p>0,05)$ entre os tratamentos até o final do experimento (Figura 1A). O consumo de concentrado, não diferiu até os 48 dias de vida ( $p>0,05)$, porém, no último período experimental $(49-60$ dias), o consumo foi maior $(p \leq 0,05)$ para os animais que receberam Leite de ovelha em relação aos do Sucedâneo 36\% LAC e aos do Sucedâneo $29 \%$ LAC e, estes dois últimos, não diferiram $(p>0,05)$ entre si (Figura 1B). O consumo de feno não diferiu $(p>0,05)$ até os 39 dias de vida, porém, dos 40 aos 60 dias de idade dos cordeiros, os animais alimentados com Leite de ovelha apresentaram consumo superior $(p \leq 0,05)$ aos que receberam Sucedâneo $29 \%$ LAC, com comportamento intermediário para os cordeiros do Sucedâneo 36\% LAC, que foram similares aos demais (Figura 1C).
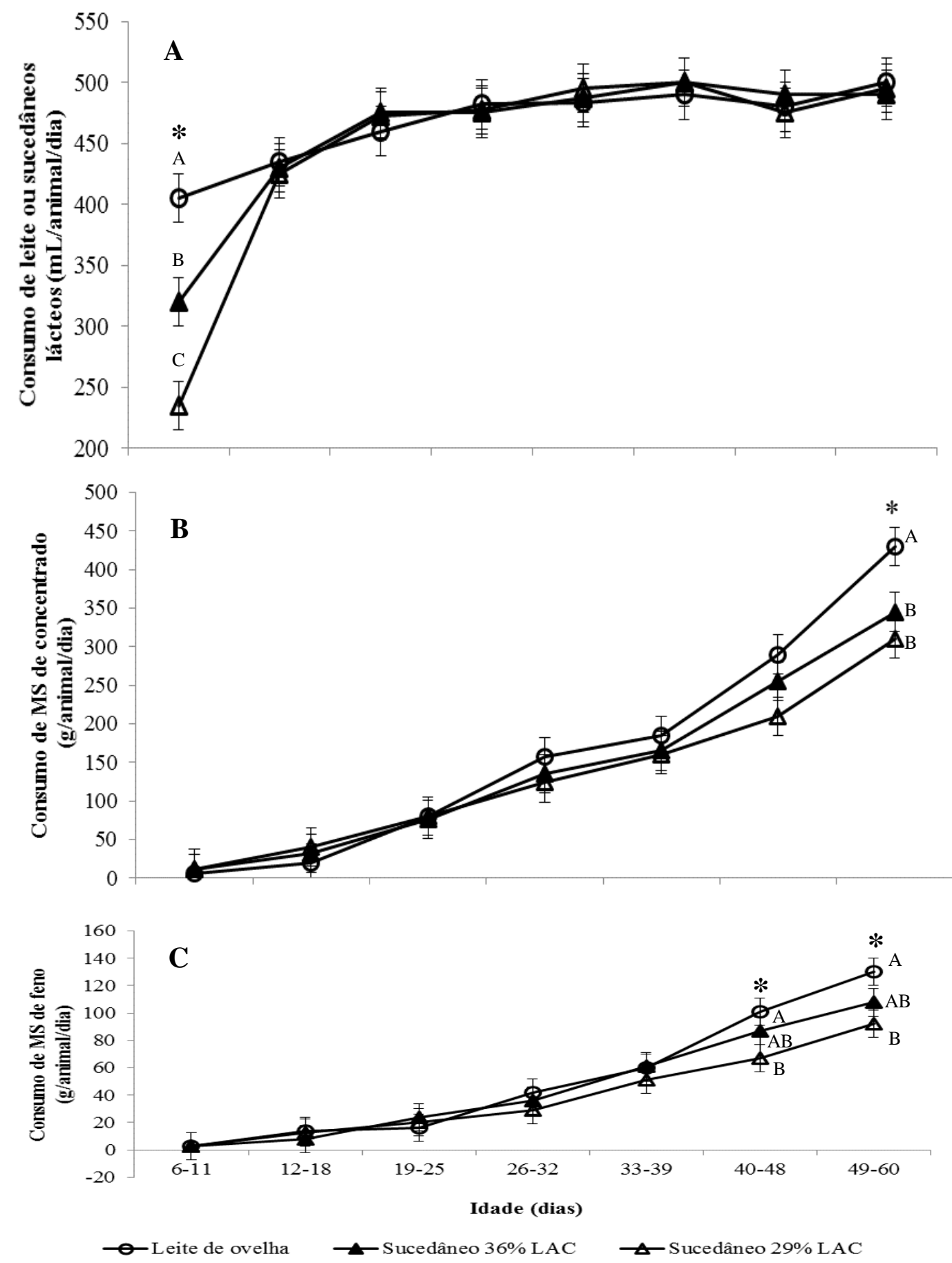

Figura 1. Consumo de leite de ovelha/sucedâneos lácteos, concentrados e feno pelos cordeiros. ${ }^{*}$ Representa diferença significativa $(p \leq 0,05)$ entre os tratamentos em cada idade.

Figure 1. Intake of ewes's milk/milk replacers, concentrates and hay by lambs. ${ }^{*}$ Represents significant difference $(p \leq 0.05)$ between treatments at each age. 
O peso corporal final e o ganho médio diário dos cordeiros alimentados com Leite de ovelha foram superiores $(p \leq 0,05)$ aos do Sucedâneo $29 \%$ LAC e, os do Sucedâneo $36 \%$ LAC não diferiram dos demais $(p>0,05)$. $O$ consumo de leite de ovelha ou dos sucedâneos diluídos em água não diferiram $(p>0,05)$, porém quando analisado o consumo de MS de leite de ovelha ou sucedâneos, os cordeiros que receberam Leite de ovelha foram superiores $(p \leq 0,05)$ aos dos Sucedâneos 36 e $29 \%$ LAC, os quais foram similares entre si $(p>0,05)$. O consumo médio de feno durante todo o experimento, não foi alterado pelos tratamentos ( $>0,05$ ), porém o consumo de concentrado e total (feno + concentrado + leite de ovelha/sucedâneos) foram superiores $(p \leq 0,05)$ para os cordeiros que receberam Leite de ovelha em relação aos do Sucedâneo $29 \%$ LAC e, os cordeiros alimentados com Sucedâneo 36\% LAC não diferiram $(p>0,05)$ dos demais. Esses resultados refletiram na conversão alimentar, que foi melhor $(p \leq 0,05)$ para os animais do tratamento Leite de ovelha em relação aos do Sucedâneo $29 \%$ LAC e, os cordeiros do tratamento Sucedâneo $36 \%$ LAC não diferiram dos demais (Tabela 3).

Tabela 3. Consumo e desempenho de cordeiros recebendo diferentes sucedâneos lácteos ou leite de ovelha.

Table 3. Intake and performance of lambs receiving different milk replacers or ewe's milk.

\begin{tabular}{|c|c|c|c|c|c|}
\hline \multirow[b]{2}{*}{ Variáveis $^{2}$} & \multicolumn{4}{|c|}{ Tratamentos $^{1}$} & \multirow[b]{2}{*}{ Valor-p3 } \\
\hline & $\begin{array}{c}\text { Leite de } \\
\text { ovelha }\end{array}$ & $\begin{array}{c}\text { Sucedâneo } \\
36 \% \text { LAC }\end{array}$ & $\begin{array}{c}\text { Sucedâneo } \\
29 \% \text { LAC }\end{array}$ & EPM & \\
\hline $\mathrm{PCl}(\mathrm{kg})$ & 4,97 & 4,93 & 5,04 & 0,396 & 0,9791 \\
\hline $\mathrm{PCF}(\mathrm{kg})$ & $18,38^{a}$ & $15,39^{\mathrm{ab}}$ & $13,17^{b}$ & 1,059 & 0,0286 \\
\hline GMD (kg) & $0,236^{a}$ & $0,186^{\mathrm{ab}}$ & $0,153^{b}$ & 0,015 & 0,0137 \\
\hline \multicolumn{6}{|l|}{ Consumo (média/animal/dia) } \\
\hline Leite ou Sucedâneo - diluído (mL) & 468,57 & 468,32 & 465,93 & 8,858 & 0,9688 \\
\hline Leite ou Sucedâneo (g de MS) & $85,36^{a}$ & $75,73^{b}$ & $75,34^{b}$ & 1,612 & 0,0002 \\
\hline Feno (g de MS) & 52,00 & 46,50 & 39,50 & 2,345 & 0,0724 \\
\hline Concentrado (g de MS) & $167,00^{\mathrm{a}}$ & $145,50^{\mathrm{ab}}$ & $134,00^{\mathrm{b}}$ & 5,041 & 0,0414 \\
\hline Total (g de MS) & $305,12^{a}$ & $268,66^{\mathrm{ab}}$ & $248,69^{b}$ & 8,075 & 0,0349 \\
\hline $\mathrm{CA}$ & $1,34^{a}$ & $1,50^{\mathrm{ab}}$ & $1,81^{b}$ & 0,054 & 0,0191 \\
\hline
\end{tabular}

'Sucedâneo 36\% LAC, sucedâneo lácteo contendo 36\% de lactose (Sprayfo Red, Trouw Nutrition, Holanda) e; Sucedâneo 29\% LAC, sucedâneo lácteo contendo 29\% de lactose (produto sem nome comercial - em fase de teste, Raupp Comércio e Importação Ltda., Brasil).

${ }^{2} \mathrm{PCI}$, peso corporal inicial; PCF, peso corporal final; GMD, ganho médio diário; Leite ou Sucedâneo - diluído, sucedâneos lácteos diluídos em água na proporção de 1:6 respectivamente; Leite ou sucedâneo ( $\mathrm{g}$ de MS), quantidade de MS de leite de ovelha ou sucedâneo consumido; Total, somatório das ingestões de leite/sucedâneo, concentrado e feno; CA, conversão alimentar (consumo/ganho de peso).

${ }^{3} p \leq 0,05$ representa diferença significativa entre os tratamentos.

Não houve efeito de tratamento $(p>0,05)$ no PC dos animais até os 25 dias de idade. No entanto, dos 32 aos 60 dias de idade, os animais alimentados com Leite de ovelha apresentaram maior $P C(p \leq 0,05)$ que os do Sucedâneo 29\% LAC, e os cordeiros do tratamento Sucedâneo $36 \%$ LAC não diferiram $(p>0,05)$ dos demais (Figura 2). Não foi observado efeito da dieta empregada $(p>0,05)$ na taxa de mortalidade ou diarreia (Tabela 4).

Tabela 4. Taxa de mortalidade e ocorrência de diarreia de cordeiros consumindo diferentes sucedâneos lácteos ou leite de ovelha.

Table 4. Mortality and diarrhea rate of lambs consuming different milk replacers or ewes's milk.

\begin{tabular}{|c|c|c|c|c|c|}
\hline \multirow[b]{2}{*}{ Variáveis (\%) } & \multicolumn{4}{|c|}{ Tratamentos $^{1}$} & \multirow[b]{2}{*}{ Valor-p $p^{2}$} \\
\hline & $\begin{array}{c}\text { Leite de } \\
\text { ovelha }\end{array}$ & $\begin{array}{c}\text { Sucedâneo } \\
36 \% \text { LAC }\end{array}$ & $\begin{array}{c}\text { Sucedâneo } \\
29 \% \text { LAC }\end{array}$ & EPM & \\
\hline Mortalidade & 8,33 & 0,00 & 8,33 & 6,80 & 0,6111 \\
\hline Diarreia (1 vez) & 25,00 & 33,33 & 33,33 & 13,84 & 0,8865 \\
\hline $\begin{array}{l}\text { Diarreia (2 vezes ou mais) } \\
{ }^{1} \text { Sucedâneo } 36 \% \text { LAC, sucedâneo lácteo } \\
\text { Sucedâneo } 29 \% \text { LAC, sucedâneo lácteo cc } \\
\text { Raupp Comércio e Importação Ltda., Brasil) } \\
{ }^{2} p \leq 0,05 \text { representa diferença significativa en }\end{array}$ & $\begin{array}{l}\frac{8,33}{\text { endo } 36 \%} \\
\text { do } 29 \% \text { d } \\
\text { tratamen }\end{array}$ & $\begin{array}{l}16,67 \\
\text { lactose }(\mathrm{Spr} \\
\text { ose (produto }\end{array}$ & $\begin{array}{c}\text { 8,33 } \\
\text { Red, Trouw } \\
\text { nome come }\end{array}$ & $\frac{9,40}{\text { Nutrition, }}$ & $\begin{array}{l}0,7712 \\
\text { landa) e; } \\
\text { de teste, }\end{array}$ \\
\hline
\end{tabular}




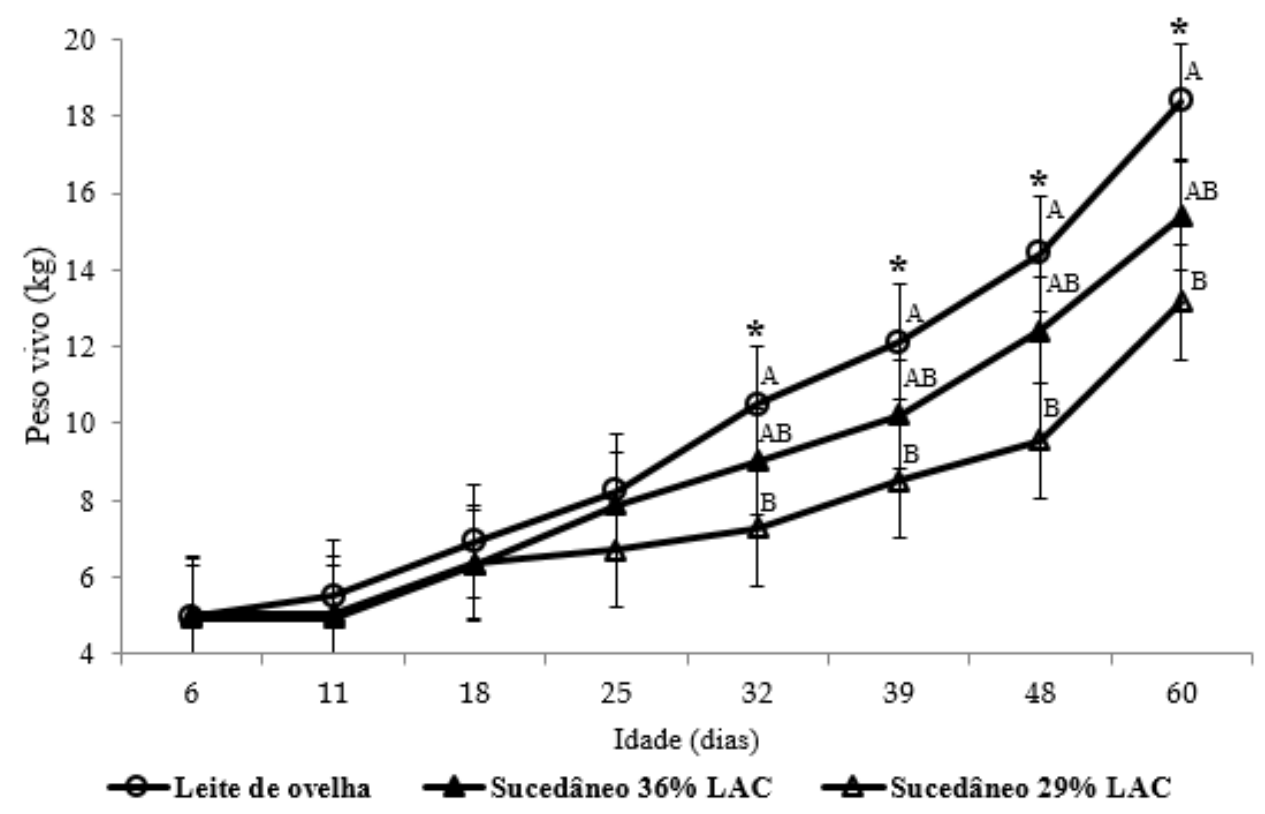

Figura 2. Evolução do peso vivo dos cordeiros consumindo diferentes sucedâneos lácteos ou leite de ovelha. *Representa diferença significativa $(p \leq 0,05)$ entre os tratamentos em cada idade.

Figure 2. Evolution in the body weight of lambs consuming different milk replacers or ewes's milk. ${ }^{*}$ Represents significant difference $(p \leq 0.05)$ between treatments at each age.

\section{DISCUSSÃO}

Apesar de não ser observada alteração entre o consumo médio de leite de ovelha ou sucedâneos, quando avaliado o consumo de sólidos oriundo desses ( $g$ de $M S$ ), foi observada maior ingestão pelos animais que consumiam leite de ovelha. Isso acontece devido a concentração de MS ser superior nesse em relação aos sucedâneos diluídos. Esse maior consumo de sólidos oriundos do leite, associado a alta digestibilidade de seus componentes, auxilia em explicar o maior ganho de peso dos cordeiros alimentados com Leite de ovelha em relação aos do Sucedâneo $29 \%$ LAC.

Em experimento com cordeiros lactentes, a utilização de sucedâneo com composição semelhante ao utilizado no presente estudo, com PB, 22\%; EE, 18\%; MM, 9\%; Lactose, 36\%, (Sucedâneo 36\% LAC) por 42 dias, resultou em menor ganho de peso para os animais alimentados artificialmente (OCAK \& CANKAYA 2013). Porém no referido estudo, os animais do grupo controle permaneciam junto com as mães amamentando, diferente do presente trabalho, em que o leite de ovelha era fornecido manualmente. Segundo NAPOLITANO \& ROSA (2008) a separação precoce dos cordeiros das mães, causa alto estresse emocional, tanto para os cordeiros como para as ovelhas, e isso reflete em menor consumo de alimento, aumento nas concentrações de cortisol, diminuição na resposta imunológica e no ganho de peso dos cordeiros. No entanto, neste estudo, todos os cordeiros passaram pelo mesmo estresse de separação das mães, e foi fornecido a mesma quantidade de leite ou sucedâneos para todos os animais, o que proporcionou aos animais avaliados as mesmas condições ambientais.

Alguns trabalhos observaram que cordeiros consumindo sucedâneos lácteos apresentaram ganho de peso semelhante aos que permaneceram amamentando nas próprias mães. No trabalho de EMSEN et al. (2004) a utilização de sucedâneo lácteo (24,5\% PB, 19\% EE, 0,5\% FDN, e 9,5\% MM) para cordeiros da raça Awassi não alterou o ganho de peso até os 45 dias de idade. Resultado semelhante foi encontrado por HERNÁNDEZ-CASTELLANO et al. (2015), no qual o fornecimento de sucedâneo lácteo $(23,6 \%$ PB, $22,7 \%$ $\mathrm{EE}, 0,0 \% \mathrm{FDN}, 8,2 \% \mathrm{MM}$ ) ou leite de vaca em pó integral para cordeiros da raça Canária não alterou a idade que os animais atingiram $10 \mathrm{~kg}$ de peso vivo ( \pm 30 dias), em relação aos cordeiros amamentando nas próprias mães.

O consumo de concentrado e feno foi afetado pela alimentação com leite de ovelha ou sucedâneo lácteo. O fornecimento de leite de ovelha proporcionou maior ganho de peso que o Sucedâneo $29 \%$ LAC, o que acarretou maior consumo de concentrado e feno pelos cordeiros. Os ovinos, assim como outros ruminantes, apresentam correlação positiva entre peso vivo e consumo de matéria seca, assim, animais mais pesados apresentam consumo absoluto ( $\mathrm{kg}$ de MS) superior aos mais leves (NRC 2007). Além disso, o leite de ovelha pode ter proporcionado melhor desenvolvimento do rúmen, e, proporcionado melhor 
digestibilidade da dieta sólida. Dietas mais digestíveis apresentam maior taxa de passagem pelo rúmen (HUNTINGTON \& GIVENS 1995) e isso pode refletir em maior consumo. Além disso, a presença de ingredientes vegetais na composição dos sucedâneos lácteos, associado a baixa produção enzimática (principalmente amilase) na fase inicial de aleitamento, pode ter causado menor digestibilidade dos sucedâneos e desenvolvimento do rúmen em relação aos animais consumindo leite de ovelha, e isso pode ter refletido no consumo de concentrado e feno.

A alimentação com leite de ovelha ou sucedâneos lácteos não influenciaram a taxa de mortalidade e a ocorrência de diarreia dos cordeiros. O aleitamento artificial pode afetar o sistema imunológico dos cordeiros, principalmente nos primeiros dias de vida, pois esses dependem da absorção de fatores do sistema complemento providos pelo colostro (OSWALD et al. 1990). Segundo HERNÁNDEZ-CASTELLANO et al. (2015) o consumo de sucedâneos lácteos, em comparação com o leite de ovelha por cordeiros, reflete em menor concentração plasmática de imunoglobulinas (IgG e $\operatorname{lgM}$ ) e atividade do sistema complemento, até cinco dias após o nascimento, no entanto, essas diferenças desaparecem no período do desmame. Neste estudo, os cordeiros permaneceram com suas mães até aproximadamente 11 dias após o nascimento, idade na qual o sistema imunológico é pouco dependente da absorção de fatores do sistema complemento, assim o fornecimento de sucedâneos não prejudicou o sistema imune e, dessa forma, não afetou a taxa de mortalidade ou a ocorrência de diarreia.

\section{CONCLUSÃO}

O fornecimento de sucedâneo lácteo com $36 \%$ de lactose pode ser utilizado para cordeiros lactentes como substituto ao leite de ovelha sem prejuízos ao desempenho e saúde. Sucedâneos lácteos com $29 \%$ de lactose acarretam menor ganho de peso e consumo total de alimentos em relação aos cordeiros consumindo leite de ovelha.

Experimentos futuros devem avaliar sucedâneos lácteos com maior proporção de $E E$, que quando diluídos em água apresentem composição semelhante ao leite de ovelha (aproximadamente 8,6\% de EE).

\section{REFERÊNCIAS}

AOAC. 1990. Association of Official Analytical Chemists. Official methods of analysis. 15.ed. Arlington: AOAC International. 1117p.

EMSEN E et al. 2004. Growth performance of Awassi lambs fed calf milk replacer. Small Ruminant Research 53: 99102.

HERNÁNDEZ-CASTELLANO LE et al. 2015. The effect of milk source on body weight and immune status of lambs. Livestock Science 175: 70-76.

HUNTINGTON JA \& GIVENS DI. 1995. The in situ technique for studying the rumen degradation of feeds: A review of the procedure. Nutrition Abstract and Reviews 65: 63-93.

LANZA M et al. 2006. Lamb meat quality as affected by a natural or artificial milk feeding regime. Meat Science 73: 313318.

SAS. 2013. Statistical Analysis System, versão 9.4. North Carolina: SAS Institute Incorporated.

NAPOLITANO F \& ROSA G. 2008. Welfare implications of artificial rearing and early weaning in sheep. Applied Animal Behaviour Science 110: 58-72.

NRC. 2007. National Research Council. Nutrient requirements of small ruminants. 7.ed. Washington: National Academic Press. 384p.

OCAK S \& CANKAYA S. 2013. A novel method of analyzing rearing system on lamb growth and farm profitability. African Journal of Agricultural Research 8: 495-499.

OSWALD IP et al. 1990. Classical and alternative pathway hemolytic activities of ovine complement: variations with age and sex. Veterinary Immunology and Immunopathology 24: 259-266.

SNIFFEN CJ et al. 1992. A net carbohydrate and protein system for evaluating cattle diets: Il. Carbohydrate and protein availability. Journal of Animal Science 70: 3562-3577.

UMBERGER HS. 1997. Profitable artificial rearing of lambs. Animal and Poultry Science, Publication №. 410-023. Virginia Cooperative Extension.

VAN SOEST PJ et al. 1991. Methods for dietary fiber, neutral detergent fiber, and nonstarch polysaccharides in relation to animal nutrition. Journal of Dairy Science 74: 3583-3597. 